\title{
How schools teach our children to be fat
}

\author{
Diane Kelsall MD MEd
}

See also pages 389 and 411 as well as www.cmaj.ca/lookup/doi/10.1503/cmaj.150259 and www.cmaj.ca/lookup/doi/10.1503/cmaj.141285

$\mathrm{O}$ ur children are getting fatter. They eat more and move less. Although nearly $85 \%$ of children aged three to four years meet activity levels recommended in Canadian guidelines, this falls to $4 \%$ in teens. ${ }^{1}$ Most of our overweight or obese children will not outgrow their weight problem. They are developing adult diseases like hypertension and diabetes. Yet, our schools hinder the fight against obesity in our youth.

Let's look at a typical day for Canadian high school students. Their school day starts early, often well before $9 \mathrm{am}$. They are likely driven or take the bus to school. They are tired when they arrive and sit for most of the day. Physical education classes are usually not required after grade 9. Lunch may be rushed, and food options available in the school may be high in fat or sugar. At lunch or after classes, some students may participate in sports, but most don't. Students have hours of homework resulting in extended screen time. They go to bed late, and the cycle starts again. No wonder nearly one-third of our school-aged children is overweight or obese. ${ }^{2}$

The school's influence on diet and exercise extends far beyond the physical education curriculum. Schools have an important role in helping our children to be healthy now and teaching them how to be healthy adults. Here are some things schools can do to support our children in acquiring healthy habits.

Schools can help students to develop a positive attitude toward physical activity by making exercise the norm. Walking or cycling to school is a good start. With usual walk limits for taking the bus set at several kilometres, students who walk to school may get close to meeting daily activity requirements. ${ }^{3}$ There is a move, however, in some urban jurisdictions to reduce walk limits to a paltry $1 \mathrm{~km}$ or less. Yet even taking public transportation affords more opportunity for exercise than being driven by parents.

Mandating physical education classes throughout all school years, rather than just earlier grades, may also send the message that exercise is a part of daily life. These classes should include enough sustained, vigorous exercise to help students meet recommended activity levels, rather than the 20-minute requirement in some jurisdictions. Some schools offer personal fitness classes as part of the curriculum.

Regardless of physical activity level, however, lengthy sitting time has been shown to be a risk factor for early death in adults. ${ }^{4}$ A peek into most high school classrooms will show rows of students sitting for classes that are often 75 minutes in length, among the longest in the world. This sends the message that being sedentary is acceptable. Beyond physical education classes, getting students moving during school hours takes creativity. Some schools have instituted morning cardio exercise programs. Others have fitness facilities available to students in their free time. Teachers may emphasize kinesthetic learning, institute short exercise breaks or take students outside. Reducing class length is an option, but may require a longer school year.
There has been a move toward schools selling foods and drinks with better nutritional quality, but not in all jurisdictions. Schools often reward students with fast food. Although older students may buy junk food elsewhere, schools still have an opportunity to model and teach healthy eating habits. In Japan, for example, food education is part of the compulsory curriculum.

In high school, later start times may help. Teens have a different circadian rhythm from adults, preferring to stay up late and sleep later in the morning. Although Canadian high schools have a later start than in some jurisdictions, many teens get far less than the recommended nine to ten hours of sleep. Like adults, tired adolescents are at increased risk of obesity. ${ }^{5}$

Obesity is a complex disease and prevention requires multilevel intervention. It starts with the individual and family making good choices around exercise and food intake, but broader societal support is necessary. Some multifactorial school-based interventions have been shown to improve rates of overweight or obesity and other measures of adiposity. ${ }^{6,7}$ Later start times in high school lead to more sleep and less caffeine intake in students, and, as a bonus, less absenteeism and improved test scores. ${ }^{8}$

Drastically changing our schools to help our children will require determination and support from all Canadians and levels of government. It will not be easy. But think about the smoking areas that used to exist in our high schools and you can see what can be achieved when we choose to do the right thing for our children.

\section{References}

1. Is Canada in the running? The 2014 Active Healthy Kids Canada report card on physical activity for children and youth. Toronto: Active Healthy Kids Canada; 2014

2. Roberts KC, Shields M, de Groh M, et al. Overweight and obesity in children and adolescents: results from the 2009 to 2011 Canadian Health Measures Survey. Health Rep 2012;23:37-41.

3. Canadian physical activity guidelines and Canadian sedentary behaviour guidelines. Ottawa: Canadian Society for Exercise Physiology; 2012.

4. Biswas A, Oh PI, Faulkner GE, et al. Sedentary time and its association with risk for disease incidence, mortality, and hospitalization in adults: a systematic review and meta-analysis. Ann Intern Med 2015;162:123-32 10.7326/M14-1651.

5. Suglia SF, Kara S, Robinson WR. Sleep duration and obesity among adolescents transitioning to adulthood: Do results differ by sex? J Pediatr 2014;165:750-4.

6. Foster GD, Linder B, Baranowski T, et al.; HEALTHY STUDY GROUP. A schoolbased intervention for diabetes risk reduction. N Engl J Med 2010;363:443-53.

7. Foster GD, Sherman S, Borradaile KE, et al. A policy-based school intervention to prevent overweight and obesity. Pediatrics 2008;121:e794-802.

8. Wahlstrom K, Dretzke B, Gordon M, et al. Examining the impact of later school start times on the health and academic performance of high school students: a multi-site study. St. Paul (MN): University of Minnesota, Center for Applied Research And Educational Improvement; 2014.

Competing interests: See www.cmaj.ca/site/misc/cmaj_staff.xhtml.

Affiliation: Deputy Editor, CMAJ

Correspondence to: $C M A J$ editor, pubs@cmaj.ca

CMAJ 2015. DOI:10.1503/cmaj.150117 